\title{
Análise de custos gerados pela assistência técnica em edifícios classe A
}

\author{
F. F. Gaedke ${ }^{1}$, A. Lorenzi ${ }^{2}$, L.S. Lorenzi ${ }^{2 *}$ \\ *Autor de Contacto: 1uciani.lorenzi@gmail.com \\ ${ }^{1}$ Departamento de Engenharia Civil, Escola de Engenharia, Universidade Federal do Rio Grande do Sul, \\ Porto Alegre, Brasil \\ ${ }^{2}$ Departamento de Engenharia Civil, Escola de Engenharia, Instituto de Desempenho da UFRGS, Universidade \\ Federal do Rio Grande do Sul, Porto Alegre, Brasil
}

\begin{abstract}
RESUMO
As empresas da construção civil estão precisando produzir cada vez mais em menor tempo devido ao crescimento na construção de condomínios residenciais e estão investindo cada vez mais em setores de atendimento aos clientes buscando reestabelecer a confiança do usuário na marca. $\mathrm{O}$ setor de assistência técnica o responsável pela correção das manifestações patológicas. O presente artigo contempla a análise das principais causas geradoras de solicitações de assistência técnica e os principais custos para resolução dessas ocorrências em empreendimentos de classe A. Para isso, realiza-se, uma breve contextualização sobre o cenário atual e os conceitos abordados, a metodologia utilizada e é feita a análise de um estudo de caso utilizando o banco de dados de uma construtora e incorporadora localizada na cidade de Porto Alegre.
\end{abstract}

Palabras clave: Assistência Técnica; Custos; Manifestações Patológicas.

Citar como: F. F. Gaedke, A. Lorenzi, L.S. Lorenzi (2021), "Análise de custos gerados pela assistência técnica em edifícios classe A", CONPAT 2021, XVI, pp. xxx-xxx, DOI: http://dx.doi.org/xxxxxxxxxx

\section{RESUMEN}

Las empresas constructoras están necesitando producir cada vez más en menos tiempo debido al crecimiento en la construcción de condominios residenciales y están invirtiendo cada vez más en sectores de atención al cliente que buscan restablecer la confianza del usuario en la marca. El 
sector de asistencia técnica se encarga de corregir las manifestaciones patológicas. El presente artículo contempla el análisis de las principales causas que generan solicitudes de asistencia técnica y los principales costos para la solución de estas ocurrencias en empresas clase A. Para ello, se realiza una breve contextualización sobre el escenario actual y los conceptos abordados, la metodología utilizada y se realiza un análisis de un estudio de caso utilizando la base de datos de una empresa constructora y promotora ubicada en la ciudad de Porto Alegre.

Palabras clave: Asistencia técnica; Costos; Manifestaciones patológicas.

\begin{abstract}
The construction companies are needing to produce more and more in less time due to the growth in the construction of residential condominiums. The companies have more investing in customer service sectors seeking to re-establish the user's trust. The technical assistance sector is responsible for correcting the pathological manifestations. This article contemplates the analysis of the main causes that generate requests for technical assistance and the main costs for solving these occurrences in class A buildings. For this, a brief contextualization is made about the current scenario and the concepts addressed, the methodology used and an analysis of a case study is carried out using the database of a construction company and developer located in the city of Porto Alegre.
\end{abstract}

Keywords: Palabras clave: Technical Assistance; Costs; Pathological Manifestations.

\title{
1. INTRODUÇÃO
}

A construção civil é caracteriza-se por ser um setor heterogêneo e diversificado, tanto de produtos e serviços, quanto de seus agentes produtores. Para Figuerêdo (2017) a Construção Civil apresenta uma representatividade do mercado e para a economia do país, considerando que é uma atividade econômica muito expressiva e importante para o desenvolvimento do Produto Interno Bruto e que tem efeitos positivos na empregabilidade da mão de obra.

A Pesquisa Anual da Indústria da Construção - PAIC, segundo IBGE (2020), registrou a existência de 126.316 empresas ativas, que realizaram incorporações, obras e/ou serviços correspondendo R\$ 172,6 bilhões do Produto Interno Bruto - PIB, demonstrando uma participação majoritária das empresas na geração de renda setorial. Dentre essa parcela edificações gera a maior parcela do PIB $(41,6 \%)$, seguido por infraestrutura $(31,4 \%)$ e por serviços especializados $(27 \%)$, onde edificações apresenta a maior relevância para o setor, tanto do ponto de vista da geração de postos de trabalho como do de participação no PIB. No mercado de edificações o mercado de habitações é o mais representativo abrangendo $61 \%$, ou seja, $\mathrm{R} \$ 43,6$ bilhões.

Dentro dessa parte do setor destinada a edificações habitacionais existe uma parcela de prédios residenciais para a Classe A, sendo um dos nichos de negócios que cresce no país. Uma das razões é a migração do público Classe A de casas para prédios, pois oferecem maior segurança em decorrência do aumento da violência no país. Diante desse cenário, ocorreu o crescimento acelerado da oferta de imóveis Classe A e, por consequencias, "boas práticas" construtivas foram deixadas em segundo plano. A premissa era construir mais em menor tempo, tendo como consequência uma escassez no mercado de mão de obra qualificada e um controle da produção das obras deficientes. A soma desses fatores são constatados com o decorrer dos anos, por vezes denominados vícios ocultos, impactando na vida dos proprietários gerando um passivo emocional aos mesmos e, às empresas, gastos com a resolução de manifestações patológicas. 
Com a criação do Código de Defesa do Consumidor - CDC - em 1990, visando a proteção e defesa do consumidor e, por consequência, auxiliou as empresas do setor da construção civil a promoverem ações de melhorias no controle da qualidade, (SCHNEIDER, 2013). Outra ação desencadeada pelo CDC foi a preocupação constante em prestar o atendimento ao cliente, pois o mesmo não é fiel apenas ao produto de boa qualidade ou menor preço, mas na relação estabelecida com a empresa, (LASTE, 2012).

Alinhado a isso, surge o setor de assistência técnica que tem como objetivo a solução de problemas técnicos que venham a ocorrer no imóvel. Neste momento, o atendimento de ocorrências é baseado pelo período de garantia dos sistemas, que tem duração máxima de 5 anos.

Este trabalho aborda uma maneira diferente de lidar com os imóveis destinados ao público da Classe A (formador de opinião, elevado grau de exigência e conhecimento), onde a empresa estudada busca a satisfação do cliente quanto ao atendimento das demandas técnicas, sem limitador de tempo e da tabela de garantia utilizada nos demais segmentos da empresa. A premissa de atendimento a esse público é atender todas as ocorrências classificadas como procedentes, ou seja, àquelas que não forem originadas devido ao mau uso ou modificações dos sistemas por parte dos proprietários, denominadas essas como improcedentes.

Destaca-se que, neste caso, a assistência técnica tem função de retroalimentação do setor executivo através do seu banco de dados onde as solicitações feitas pelos clientes ficam registradas gerando indicadores de manifestações patológicas mais frequentes. A resolução dessas ocorrências, classificadas como procedentes, gera um custo para o setor, tanto de material como de mão de obra, sendo um indicador que também deve ser controlado pela assistência técnica e informado ao executivo, buscando assim, diagnosticar as falhas que ocorrem com maior frequência e àquelas vinculadas a um custo mais elevado para resolução do problema.

Diante desse contexto o trabalho tem por objetivo apresentar uma análise das principais causas dos atendimentos da assistência técnica e os custos vinculados para resolução das ocorrências em prédios residenciais classificados como Classe A, abrangendo um período de dois anos.

\section{REFERENCIAL TEÓRICO}

A infraestrutura nacional que utiliza sistema convencional com o uso de muita água e demanda muita mão de obra e após o acabamento, é comum o surgimento de vários problemas que precisarão ser solucionados, como por exemplo infiltração e fissuras, que necessitam de reparos ou até mesmo de um retrabalho na área afetada. Na Europa e nos Estados Unidos são utilizados processos mais industrializados e, mesmo demandando mão de obra, utiliza-se como padrão a construção seca, que não usa água e sim perfis metálicos que são montados de acordo com o projeto e depois as placas de madeira ou de outro material são fixadas, (FIGUERÊDO, 2017).

O setor construtivo brasileiro tem sido marcado pelo desenvolvimento precoce, de manifestações patológicas em sua estrutura, seja por falhas de projeto, execução ou especificação incorreta de materiais, causando o comprometimento das condições de segurança e habitabilidade, exigindo assim um elevado número de ações de manutenção de forma a sanar tais manifestações patológicas, (OLIVEIRA, MITIDIERI FILHO, 2012).

A ocorrência de manifestações patológicas de qualquer natureza em uma edificação gera a necessidade de uma futura manutenção, reforma ou revitalização para sanar tal problema. Tais práticas são onerosas e causam prejuízo e desconforto tanto para as construtoras quanto para os usuários. Assim, é fundamental que profissionais, construtoras e usuários da área de construção venham a investir constantemente na prevenção destas anomalias, como forma de garantir a durabilidade, estabilidade, segurança, desempenho das edificações, além de uma redução de custos tanto futuros quanto no decorrer da obra (LIMA, 2005). 
Nessa linha, porém voltado a clientes de imóveis de alto padrão, há a vinculação da aquisição do imóvel a um produto de qualidade e que a história, a reputação e a imagem da marca (empresa) são decisivas para a aquisição do imóvel, (BAUTZ, 2017). Esses posicionamentos mostram mais uma vez como o atendimento ao cliente tem papel de destaque na perpetuação das empresas.

$\mathrm{Na}$ busca por atender a satisfação dos clientes empresas criaram um canal de comunicação, onde a criação desse serviço possibilita às empresas um contato direto com o cliente, com inúmeras funções, sendo uma delas a de assistência técnica. (RAMOS, MITIDIERI FILHO, 2007). Uma das principais funções do atendimento aos clientes é a retroalimentação ao sistema de produção de edifícios e a apropriação de custos dos problemas patológicos, pois através do banco de dados gerado o setor exerce a função de melhoria contínua, realizando a identificação da frequência de ocorrência das manifestações patológicas nas edificações e a descoberta da causa fundamental de cada uma delas, (REZENDE, MELHADO \& MEDEIROS, 2002).

Com a retroalimentação das informações é possível uma análise periódica de quais manifestações patológicas tem ocorrido nos empreendimentos entregue, detectando possíveis problemas recorrentes e prevenindo-os nas obras futuras. (SCHNEIDER, 2013). A assistência técnica pósobra tem caráter corretivo de eventuais vícios ocultos e manifestações patológicas encontradas nas edificações que não foram causadas por mau uso ou falta de manutenção, (SILVA FILHO, SOUZA \& LEÃO FILHO, 2015).

Os custos gerados na assistência técnica não servem apenas para nortear o orçamento de produtos já existentes, mas também são primordiais na tomada de decisão para novos produtos que serão lançados no mundo, (ARAÚJO, MENDES \& MARTINS, 2018). No Brasil, a construção civil apresenta um grande impacto no desenvolvimento local e no PIB regional e os aumentos frequentes de custo na construção civil foram os grandes impulsionadores para que as empresas passassem a direcionar um maior esforço no planejamento e no monitoramento dos projetos de construção, (NETTO, et al., 2020).

\section{METODOLOGIA}

Este trabalho foi desenvolvimento por meio de uma abordagem quantitativa estruturada numa pesquisa descritiva em um estudo de caso e teve como método de trabalho um estudo de caso. Os dados analisados foram coletados de uma única empresa do setor da construção civil, como negócios immobiliários, que tem sua sede situada em Porto Alegre - RS, BRasil. A empresa é considerada de porte médio e com operação em diversos seguimentos, desde empreendimentos voltados ao público emergente até os de alto padrão, caracterizados poe Classe A.

através da coleta de informações do banco de dados de uma empresa de construção brasileira. Foram selecionados apenas os empreendimentos de Classe A da empresa, no total 8, e após análise detalhada da "planilha dinâmica da assistência técnica, local de armazenamento de ocorrências da empresa, foram selecionados 3 . O critério para os 3 selecionados foi por ainda estarem dentro do "período de garantia", que é de 5anos pela legislação brasileira, e também por apresentarem ocorrências resolvidas em um período de 2 anos, 2017 e 2018. Com esta definição, foi realizada a coleta dos dados das ocorrências geradas para atendimentos feitos pela assistência técnica. Os dados foram quantificados utilizando-se por base a causa geradora da manifestação patológica à qual o cliente solicita suporte. No levantamento foram elencadas as dez causas com o maior número de chamados de atendimentos de assistência técnica em cada empreendimento.

Também foram apurados os custos gerados pelo atendimento das ocorrências, porém, estes, por meio da exportação dos pedidos de compras já vinculados a cada empreendimento. Nesse caso, foi realizado um trabalho manual de coleta de dados diretamente do "banco de dados da empresa", pois o mesmo não possui vínculo entre as ocorrências resolvidas e os custos gerados pelos atendimentos. O processo inclui a verificação da descrição de cada pedido de compras, conferência 
de datas e fornecedores para realizar a relação de registros das solicitações no setor de suprimentos, pedido de compras, com o serviço realizado no imóvel. Os resultados obtidos foram demonstrados por tabelas e diagramas, onde buscou-se associar o valor gasto para a resolução dos chamados com a causa geradora da demanda para, assim, comparar-se o número de ocorrências criadas com o custo realizado para solução de cada grupo de causas. Este estudo foi elaborado para os dez grupos de causas que obtiveram o custo mais elevado.

\section{LEVANTAMENTO DE DADOS}

Através do banco de dados analisado, foram identificados trinta e um empreendimentos atendidos pela assistência técnica entre os anos de 2017 e 2018, sendo divididos em comerciais, residenciais, uso misto e loteamentos. A Tabela 1, apresentada a seguir, traz a quantidade de empreendimentos e de unidades por categoria. Por meio dele é possível identificar que o maior percentual, tanto de unidades como de condomínios, está na categoria residencial, tratando-se está a que possuí maior tradição na empresa.

Na categoria residencial a construtora possui empreendimentos desde o segmento emergente até o alto padrão, sendo este, apesar de apresentar o menor número de condomínios e unidades conforme o demonstrado na Tabela 2, de acabamentos mais nobres, o grupo em análise neste estudo.

Tabela 1. Categorias dos empreendimentos

\begin{tabular}{|c|c|c|c|c|}
\hline Categoria & $\begin{array}{c}\text { Quantidade de } \\
\text { empreendimentos }\end{array}$ & $\begin{array}{c}\text { Percentual de } \\
\text { empreendimentos } \\
(\%)\end{array}$ & Unidades & $\begin{array}{c}\text { Percentual de } \\
\text { unidades } \\
(\%)\end{array}$ \\
\hline Residencia & 21 & $68 \%$ & 3035 & $56 \%$ \\
\hline Comercial & 5 & $16 \%$ & 664 & $12 \%$ \\
\hline Misto & 3 & $10 \%$ & 1055 & $19 \%$ \\
\hline Loteamento & 2 & $6 \%$ & 684 & $13 \%$ \\
\hline TOTAL & 31 & $100 \%$ & 5438 & $100 \%$ \\
\hline
\end{tabular}

Tabela 2. Segmentos do empreendimentos

\begin{tabular}{|c|c|c|c|c|}
\hline Segmento & $\begin{array}{c}\text { Quantidade de } \\
\text { empreendimentos }\end{array}$ & $\begin{array}{c}\text { Percentual de } \\
\text { empreendimentos } \\
(\%)\end{array}$ & Unidades & $\begin{array}{c}\text { Percentual } \\
\text { de unidades } \\
(\%)\end{array}$ \\
\hline Alto Padrão & 8 & $38 \%$ & 225 & $7 \%$ \\
\hline Outros & 13 & $62 \%$ & 2810 & $93 \%$ \\
\hline TOTAL & 21 & $100 \%$ & 3035 & $100 \%$ \\
\hline
\end{tabular}

As informações foram compiladas através da Tabela 3, que traz a data de habite-se, o período de garantia e o número de chamados atendidos pela assistência técnica em cada ano em análise. Os empreendimentos A e B foram desconsiderados por terem sua entrega realizada em 2018, não gerando dados para análise no ano de 2017, apesar de já apresentarem um elevado número de ocorrências nos seus primeiros meses de funcionamento. Já os prédios entregues a mais de cinco 
anos possuem o período de garantia da assistência técnica expirado e um baixo registro de ocorrências no sistema, sendo excluídos dessa análise também.

Tabela 3. Informações do empreendimentos

\begin{tabular}{|c|c|c|c|c|}
\hline Empreendimento & $\begin{array}{c}\text { Data do } \\
\text { Habite-se }\end{array}$ & $\begin{array}{c}\text { Período de } \\
\text { Garantia }\end{array}$ & $\begin{array}{c}\mathbf{N}^{\mathbf{o}} \text { Chamados } \\
\text { Atendidos 2017 }\end{array}$ & $\begin{array}{c}\mathbf{N}^{\mathbf{0}} \text { Chamados } \\
\text { Atendidos 2018 }\end{array}$ \\
\hline A & $30 / 08 / 2018$ & $1^{\circ}$ Ano & 0 & 108 \\
\hline B & $14 / 05 / 2018$ & $1^{\circ}$ Ano & 0 & 234 \\
\hline C & $26 / 06 / 2017$ & $2^{\circ}$ Ano & 46 & 252 \\
\hline D & $11 / 09 / 2015$ & $4^{\circ}$ Ano & 372 & 277 \\
\hline E & $19 / 09 / 2014$ & $5^{\circ}$ Ano & 67 & 97 \\
\hline F & $10 / 12 / 2012$ & Expirado & 31 & 2 \\
\hline G & $26 / 12 / 2011$ & Expirado & 74 & 13 \\
\hline H & $16 / 09 / 2011$ & Expirado & 4 & 2 \\
\hline
\end{tabular}

Quanto aos empreendimentos analisados, conforme as delimitações e limitações apresentadas anteriormente, foram coletadas informações de três prédios da construtora, todos situados na cidade de Porto Alegre, Rio Grande do Sul. Denominados como "C", "D" e "E", são obras do tipo residenciais multifamiliar com cartas de habite-se emitidas entre 2014 e 2017.

Os empreendimentos possuem características semelhantes, conforme é possível identificar na descrição detalhada. Porém, buscando ressaltar os pontos em comum, foi criado a Tabela 4, que traz o período de garantia que se encontra o prédio, a quantidade de pavimentos totais, a área das unidades privativas, a quantidade de vagas de garagem e o número de dormitórios por apartamento.

Tabela 4: Características principais dos empreendimentos analisados.

\begin{tabular}{|c|c|c|c|c|c|}
\hline Empreendimento & $\begin{array}{c}\text { Período } \\
\text { de } \\
\text { Garantia }\end{array}$ & $\begin{array}{c}\text { Pavime } \\
\text { ntos }\end{array}$ & $\begin{array}{c}\text { Área } \\
\text { Apartame } \\
\left.\text { nto } \mathbf{( m}^{\mathbf{2}}\right)\end{array}$ & $\begin{array}{c}\text { Quantidade de } \\
\text { Vagas Garagem } \\
\text { por } \\
\text { Apartamento }\end{array}$ & $\begin{array}{c}\text { Dormitórios por } \\
\text { apartamento }\end{array}$ \\
\hline C & $2^{\text {o }}$ ano & $\begin{array}{c}15+1 \\
\text { subsolo }\end{array}$ & 304 & 4 ou 5 & $\begin{array}{c}4 \text { suítes }+1 \\
\text { dependência }\end{array}$ \\
\hline D & $4^{\text {o }}$ ano & $\begin{array}{c}15+5 \\
\text { subsolos }\end{array}$ & 220 & 3 ou 4 & $\begin{array}{c}3 \text { a } 4 \text { suítes }+1 \\
\text { dependência }\end{array}$ \\
\hline E & $5^{\circ}$ ano & $\begin{array}{c}13+1 \\
\text { subsolo }\end{array}$ & 237 & 3 & $\begin{array}{c}3 \text { suítes }+1 \\
\text { dependência }\end{array}$ \\
\hline
\end{tabular}

Após a caracterização, buscou-se classificar os empreendimentos e, para isto, seguiu-se as prerrogativas explicitas na norma ABNT NBR 12721:2006, chegando-se a denominação R16 - A para os três condomínios, que são considerados residenciais de alto padrão com até 16 pavimentos, neste trabalho caracterizados como Classe A.

O setor de assistência técnica da empresa em estudo é responsável pelo atendimento das ocorrências geradas por problemas nas unidades privativas e nas áreas comuns de todos os empreendimentos entregues. A divisão de atendimentos dessas demandas é realizada através de dois seguimentos: empreendimentos Classe A e demais condomínios. O cliente da classe A almeja uma maior qualidade do produto adquirido, então, ao ocorrerem manifestações patológicas devido 
a falhas construtivas, ele tem sua satisfação afetada. Este cliente espera que a assistência técnica seja imediata e assertiva, causando o menor impacto possível à sua rotina diária. A assistência técnica tem papel fundamental na satisfação do cliente, visto que por muitas vezes, estas intervenções promovem a interação entre empresa e cliente.

Ao se deparar com um defeito, o cliente entra em contato diretamente com a área responsável pelo atendimento, podendo enviar fotos, vídeos e informar sua disponibilidade para recebimento da visita técnica que tem como finalidade a identificação das causas e do método de correção para os problemas relatados. O registro das solicitações é realizado no sistema através da criação de ocorrências, onde o parecer técnico é inserido, bem como as causas e subcausas, os locais onde foram identificadas as falhas e demais comentários referentes ao atendimento. Nas ocorrências também é possível elaborar ordens de serviço destinas as empresas terceirizadas, que prestam o serviço em garantia ou através do pagamento efetuado pela construtora, opção utilizada apenas quando os sistemas não se encontram mais cobertos pela garantia do fornecedor.

\section{RESULTADOS}

O Empreendimento C possui o habite-se mais recente e teve um total de 298 ocorrências atendidas entre os anos de 2017 e 2018, sendo 231 destas solicitações, aproximadamente 77\%, com suas causas geradoras das manifestações patológicas enquadradas entre as principais razões para os chamados de assistência técnica nesse empreendimento. Dentre as causas estão problemas com instalações (elétricas e hidráulicas), revestimentos, esquadrias, impermeabilização, alvenaria de vedação e serviços complementares, sendo apresentada pela Figura 1, as dez causas com o maior número de chamados e a divisão percentual delas.

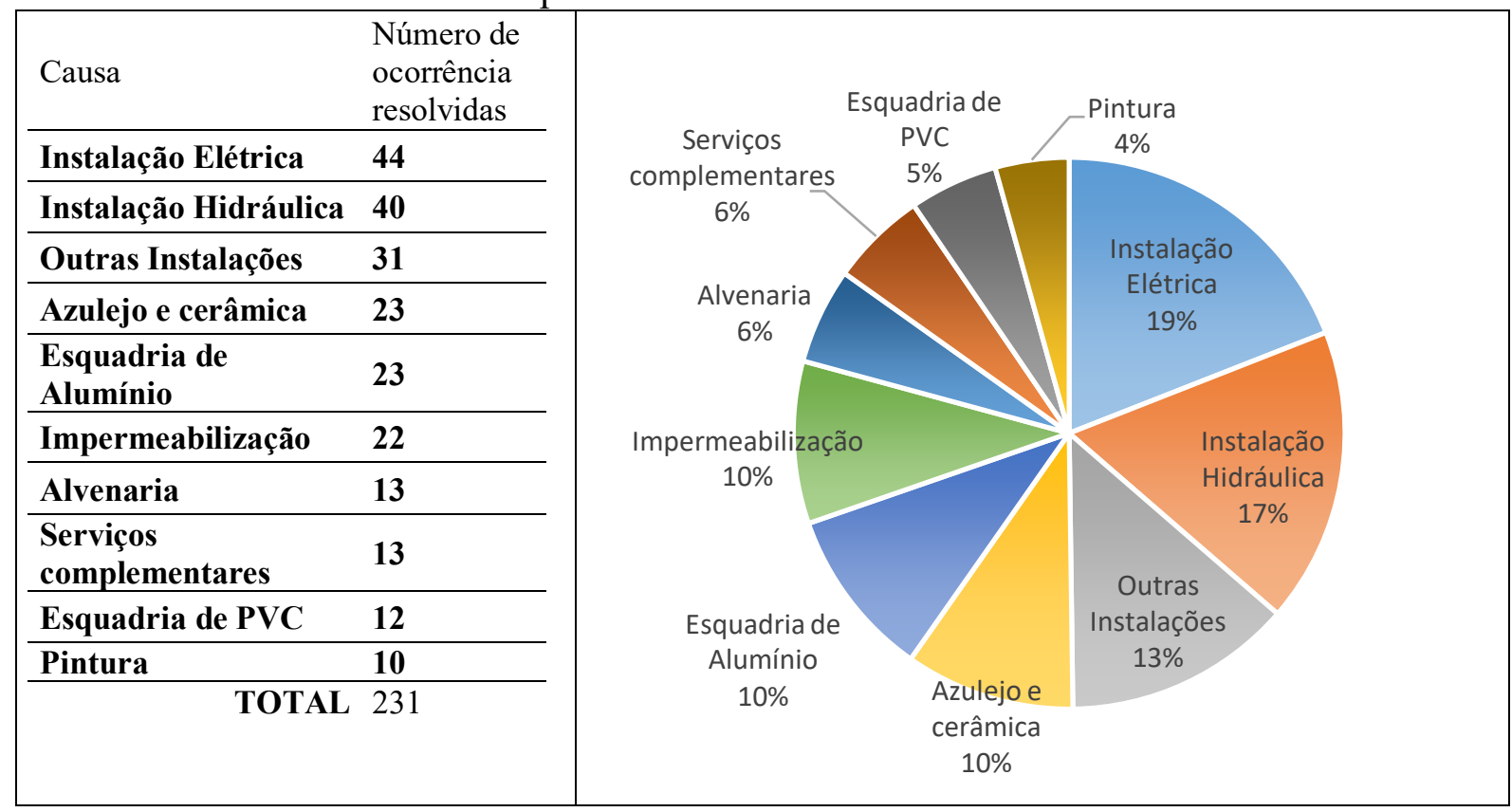

Figura 1: Principais causas vinculadas as ocorrências de assistência técnica no empreendimento C

Conforme a Figura 1, pode-se dizer que a principal falha no empreendimento $\mathrm{C}$ ocorre nas instalações elétricas, representando $19 \%$ dos principais chamados atendidos no pós-obra. Entre os vícios apresentados estão: falha nos disjuntores, curto em luminárias, tomadas e interruptores com defeitos ou apresentando curto, iluminação de emergência, instalação em desacordo com o projeto, interfones danificados e troca de materiais. 
técnica nos anos em análise, gerando 148 chamados. Dentre os problemas encontrados são mais recorrentes os atendimentos devido a vazamento na alimentação das caixas acopladas, apertos de metais, entupimentos de ralos e defeitos vinculados as bombas.

Com um percentual bem próximo das instalações hidráulicas, encontram-se as esquadrias de PVC, que foram responsáveis por 133 dos atendimentos de pós obra no empreendimento D. Onde as falhas de vedação das janelas e a regulagem das persianas são os principais itens solucionados. Sendo assim, apenas nas duas primeiras causas somam $49 \%$ dos atendimentos realizados.

A terceira causa com o maior número de chamados vinculados coincide com a mesma encontrada no empreendimento $\mathrm{C}$ e agrupa as demais instalações, excluindo-se hidráulicas e elétricas, do prédio. Este grupo tem como principais reclamações falhas no sistema de exaustão forçada e no aquecimento da piscina. Além disso, com um percentual de atendimentos semelhante ao item anterior encontram-se as esquadrias de madeiras com solicitações devido a descolamentos das lâminas e regulagem das portas.

\begin{tabular}{|c|c|c|c|}
\hline Causa & $\begin{array}{l}\text { Número de } \\
\text { ocorrência } \\
\text { resolvidas }\end{array}$ & \multirow{12}{*}{$\begin{array}{l}\text { Azulejo e } \\
\text { cerâmica; Z\% } \\
\text { Instalação } \\
\text { Elétrica; } 7 \% \\
\\
\text { Esquadria de } \\
\text { Madeira; } 9 \%\end{array}$} & \multirow[t]{2}{*}{$\begin{array}{c}\text { Serviços complementares } \\
2 \%\end{array}$} \\
\hline Instalação Hidráulica & 148 & & \\
\hline Esquadria de PVC & 133 & & \\
\hline Outras Instalações & 55 & & Hidr \\
\hline Esquadria de Madeira & 49 & & $26 \%$ \\
\hline Instalação Elétrica & 41 & & \\
\hline Azulejo e cerâmica & 39 & & \\
\hline Impermeabilização & 37 & & Es \\
\hline Alvenaria & 29 & & \\
\hline Esquadria de Alumínio & 26 & & \\
\hline $\begin{array}{l}\text { Serviços } \\
\text { complementares }\end{array}$ & 14 & & \\
\hline TOTAL & 571 & & $\begin{array}{c}\text { Outras Instalaçóes; } \\
10 \%\end{array}$ \\
\hline
\end{tabular}

Figura 3: Principais causas vinculadas as ocorrências de assistência técnica no empreendimento D.

Os defeitos relacionados as instalações elétricas, revestimentos cerâmicos e impermeabilização somam 117 ocorrências resolvidas, representando $20 \%$ entre as principais causas observadas no empreendimento D. Os problemas causados por falhas na alvenaria, nas esquadrias de alumínio e nos serviços complementares, que correspondem a $12 \%$ dos chamados atendidos. Ressalta-se que as últimas seis posições totalizam apenas 32\% dos chamados enquanto que apenas as reclamações com origem nas instalações hidráulicas obtiveram um percentual maior que um quarto entre as dez causas mais atendidas nesse condomínio.

Além de obter o maior número de solicitações, esse segundo condomínio em estudo também está vinculado ao custo mais elevado para atendimento das demandas de pós obra. Os resultados obtidos para a análise destes custos estão apresentados na Figura 4, que também traz as dez causas que registraram os maiores gastos e seus percentuais. 


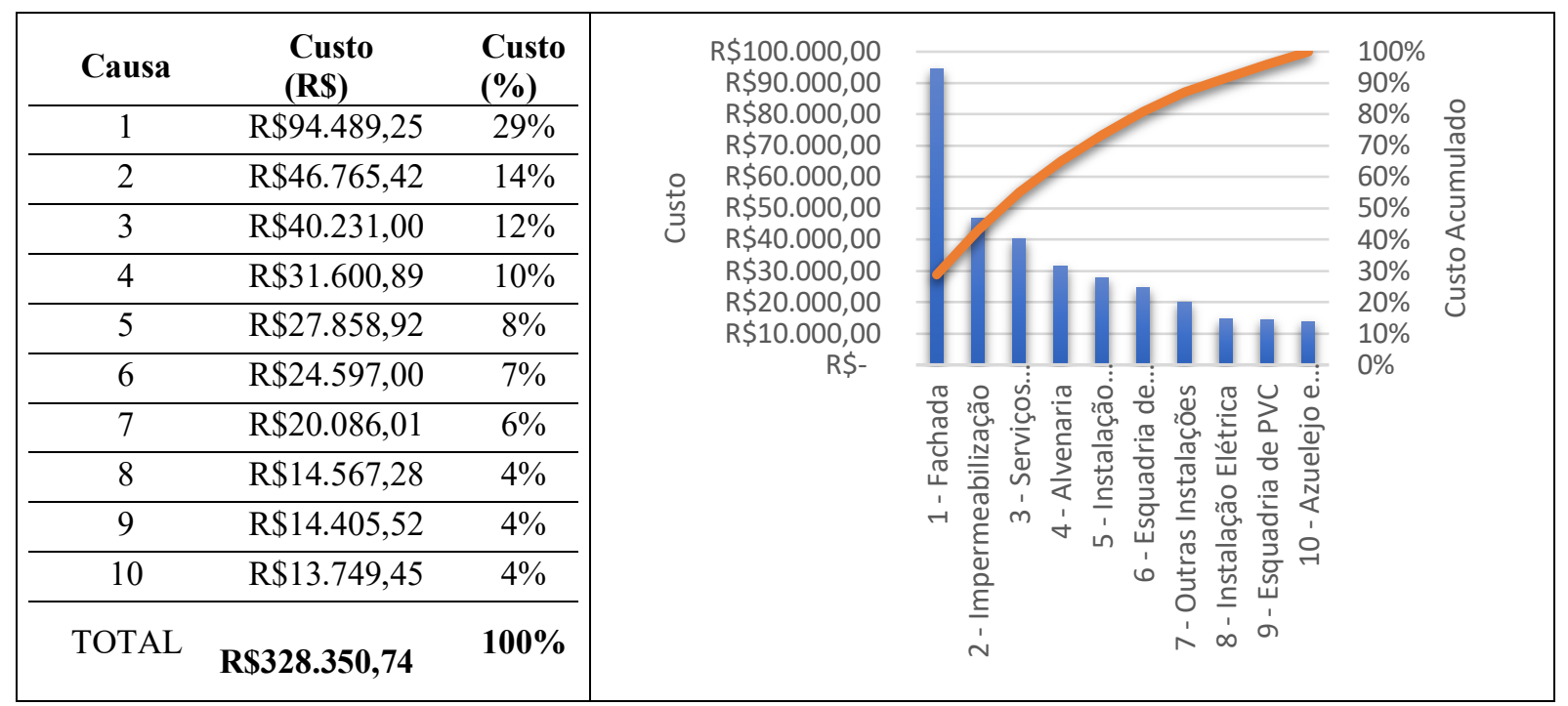

Figura 4: Principais custos relacionados as causas geradoras das ocorrências de assistências técnica no empreendimento D

Segundo os dados apresentados, os problemas vinculados a fachada do empreendimento D obtiveram o maior custo para resolução, representando $29 \%$ do total desembolsado nesse condomínio. Porém, esta manifestação patologica não está incluída entre as que obtiveram os maiores números de ocorrências, portanto, ela tem um alto custo para reparo por ocorrência gerada e uma vez que se analisam apenas os percentuais de solicitações atendidas por causas este item seria descartado. Outro ponto importante é a composição dessa fachada, revestida por pastilhas e granitos, trata-se de um produto clássico, que apesar de já ter a técnica difundida, mostra-se um ponto com falhas de controle durante a construção.

As falhas no sistema de impermeabilização estão na segunda posição do ranking de custos do condomínio D, onde acarretaram um gasto de $14 \%$ com os chamados resolvidos. Esta causa apresentou apenas 37 ocorrências, gerando assim um média de 1.264 reais para resolução de cada solicitação. Além desse item, os serviços complementares também representam um elevado custo, porém, apesar de estarem na terceira posição, apresentam uma média de 2.874 reais por ocorrência resolvida. Com esses três primeiros tópicos já se somam $55 \%$ do valor desembolsado entre os principais custos do empreendimento com habite-se em 2015.

No empreendimento $\mathrm{E}$ foi possível identificar que as três causas com o maior número de chamados resolvidos, representam mais de $50 \%$ entre os atendidos pela assistência e possuem uma pequena diferença entre si no número de ocorrência geradas, Figura 6. Além disso, apesar de ser o condomínio com maior tempo decorrido desde a entrega, ele possui o menor número de registro de ocorrências, fato observado pela comparação entre os três condomínios em estudo. Considerandose os dados apresentados na Figura 6 temos as esquadrias de PVC com o maior percentual de atendimentos vinculados, sendo $19 \%$ entre o ranking das dez causas mais atendidas. Diferente dos demais condomínios, no empreendimento $\mathrm{E}$ foram recorrentes manifestações patológicas provenientes de defeitos da fixação das esquadrias, porém também foram observados, como nos demais, falhas no sistema de vedação e ajustes no funcionamento das persianas. 


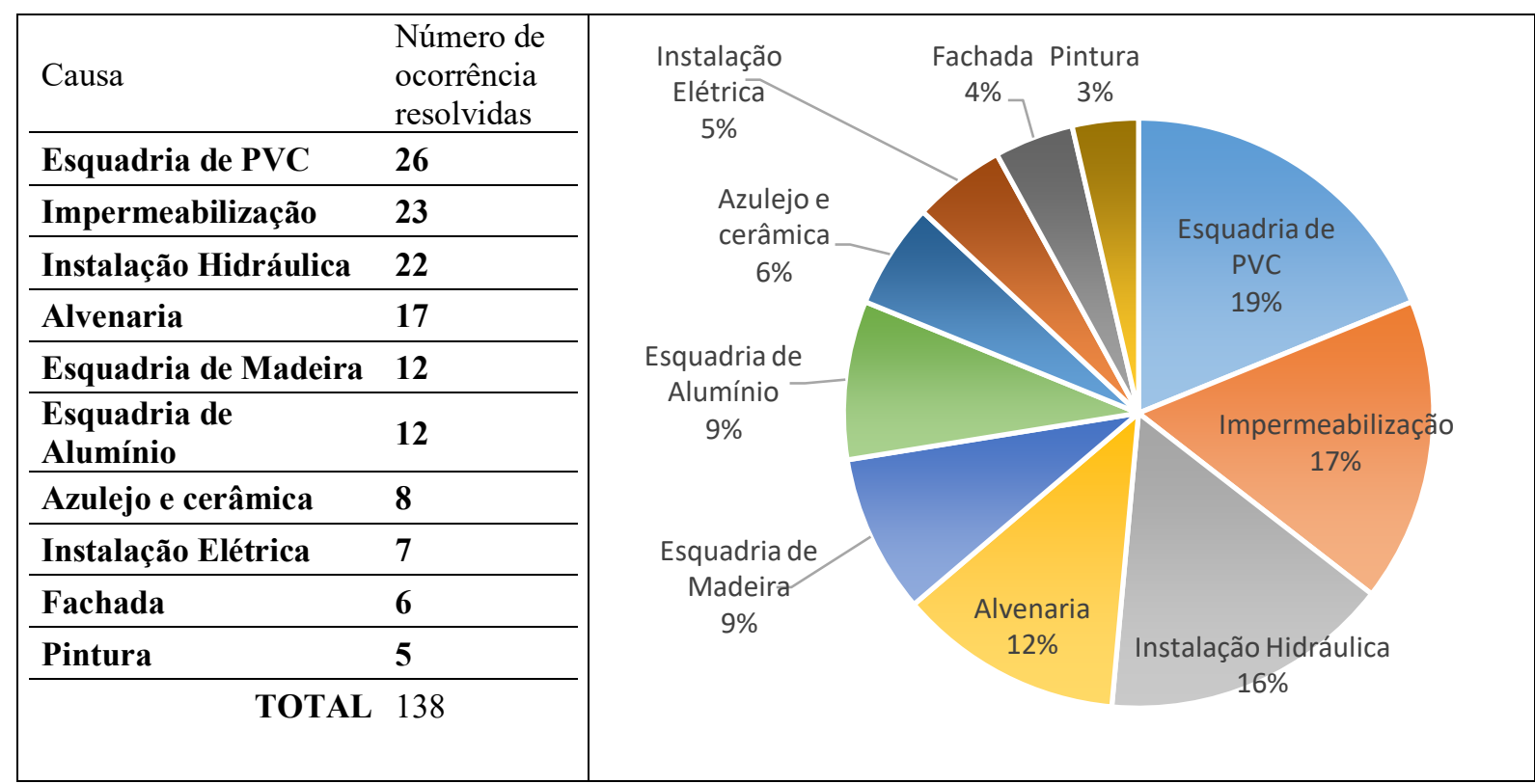

Figura 6: Principais causas vinculadas as ocorrências de assistência técnica no empreendimento E.

As falhas de impermeabilização foram responsáveis por 23 atendimentos. Porém nos condomínios $\mathrm{C}$ e D, o percentual referente a esta causa foi inferior, não estando nas primeiras posições. Os danos no sistema são variados e englobam atendimentos, principalmente, na piscina, na cortina e nos boxes de banheiros. Cabe ressaltar que este condomínio possui a menor área de uso comum entre os três em análise, o que deveria gerar um número mais reduzido de ocorrências vinculadas a áreas externas. As instalações hidrossanitárias representaram 16\% das solicitações, sendo este tópico observado nos três condomínios como um grande gerador de chamados. Com este item, somam-se $52 \%$ dos atendimentos realizados, mostrando assim, um grande impacto no número de registros dessas três primeiras causas averiguadas no empreendimento E.

A Figura 7 ilustra os custos envolvidos para resolução das solicitações do empreendimento E durante os dois anos de registro de dados. Foi utilizada a mesma metodologia aplicada anteriormente.

\begin{tabular}{|c|c|c|c|c|c|}
\hline Causa & $\begin{array}{l}\text { Custo } \\
\text { (R\$) }\end{array}$ & $\begin{array}{l}\text { Custo } \\
(\%) \\
\end{array}$ & \multirow{12}{*}{$\begin{array}{c}\mathrm{R} \$ 45.000,00 \\
\mathrm{R} \$ 40.000,00 \\
\mathrm{R} \$ 35.000,00 \\
\mathrm{R} \$ 30.000,00 \\
\mathrm{O} R \$ 25.000,00 \\
\mathrm{U} \mathrm{R} \$ 20.000,00 \\
\mathrm{U} \$ 200 \\
\mathrm{R} \$ 15.000,00 \\
\mathrm{R} \$ 10.000,00 \\
\mathrm{R} \$ 5.000,00 \\
\mathrm{R} \$-\end{array}$} & \multirow{12}{*}{$\begin{array}{lllll} \\
\end{array}$} & \multirow{12}{*}{$\begin{array}{l}100 \% \\
90 \% \\
80 \% \\
70 \% \\
60 \% \\
50 \% \\
40 \% \\
30 \% \\
20 \% \\
10 \% \\
0\end{array}$} \\
\hline 1 & $\mathrm{R} \$ 38.173,22$ & $28 \%$ & & & \\
\hline 2 & $\mathrm{R} \$ 30.470,71$ & $23 \%$ & & & \\
\hline 3 & $\mathrm{R} \$ 27.440,00$ & $20 \%$ & & & \\
\hline 4 & $\mathrm{R} \$ 12.810,41$ & $10 \%$ & & & \\
\hline 5 & $\mathrm{R} \$ 9.555,60$ & $7 \%$ & & & \\
\hline 6 & $\mathrm{R} \$ 6.102,23$ & $5 \%$ & & & \\
\hline 7 & $\mathrm{R} \$ 5.027,27$ & $4 \%$ & & & \\
\hline 8 & $\mathrm{R} \$ 1.931,80$ & $1 \%$ & & & \\
\hline 9 & $\mathrm{R} \$ 1.830,00$ & $1 \%$ & & & \\
\hline 10 & $\mathrm{R} \$ 1.174,00$ & $1 \%$ & & & \\
\hline TOTAL & R\$ $134.515,24$ & $100 \%$ & & & \\
\hline
\end{tabular}

Figura 7: Principais custos relacionados as causas geradoras das ocorrências de assistências técnica no empreendimento $\mathrm{E}$. 
Verifica-se que as falhas ocasionadas nos sistemas de impermeabilização apresentam o maior valor gasto com reparos. Esta causa possui uma grande representatividade no número de ocorrência geradas, como já foi descrito anteriormente, porém, ainda assim, reflete uma média alta para correção sendo este valor superior a 1.600 reais por ocorrência resolvida. O segundo ponto de maior impacto no custo são as manifestações patológicas geradas devido a problemas na fachada do condomínio, que também é composta por revestimento clássicos, como pastilhas e granitos. O custo despendido nesses reparos representa $23 \%$ entre os dez maiores e esta atrelado a apenas 6 ocorrências, mostrando novamente, um alto custo para resolução de cada solicitação.

Uma análise geral dos 3 empreendimentos, C, D e E evidenciou-se que 22\% das ocorrências atendidas, as instalações hidráulicas são responsáveis pela maioria dos chamados de assistência técnica para os empreendimentos classe A. O sistema utilizado nos três prédios é composto por tubulações de PVC, PPR e PEX. Além disso, nas posições 3 e 4, respectivamente, com um número de solicitações semelhantes, encontram-se os itens de outras instalações e instalações elétricas. Com isso, pode-se perceber que o grupo de instalações é o que apresenta a maior quantidade de reclamações, somando 395 que representam 42\% dentre as principais causas. Com 171 ocorrências resolvidas, a segunda causa mais vinculada a atendimentos de assistência técnica são as esquadrias de PVC, material das janelas utilizadas nos três empreendimentos. Porém, é observado que no empreendimento $\mathrm{C}$, o mais novo entre os três em análise, este tópico não está presente nas primeiras posições e como os problemas mais recorrentes são de falhas nas vedações e regulagem de persianas, este é um possível tópico que aumentará o número de solicitações com o passar do tempo. Nestas quatro primeiras causas já estão relacionadas 566 ocorrências atendidas, que representam $60 \%$ entre o grupo das principais. Além disso, os problemas de impermeabilização (8\%), revestimentos cerâmicos (7\%), esquadrias de madeira (7\%), esquadrias de alumínio (6\%), alvenaria (6\%), serviços complementares $(3 \%)$ e pintura $(3 \%)$ compõem o ranking das causas com maior número de atendimentos de assistência técnica, conforme pode ser observado na Figura 8.

\begin{tabular}{|c|c|c|c|}
\hline Causa & $\begin{array}{l}\text { Número de } \\
\text { ocorrência } \\
\text { resolvidas }\end{array}$ & \multirow{13}{*}{ 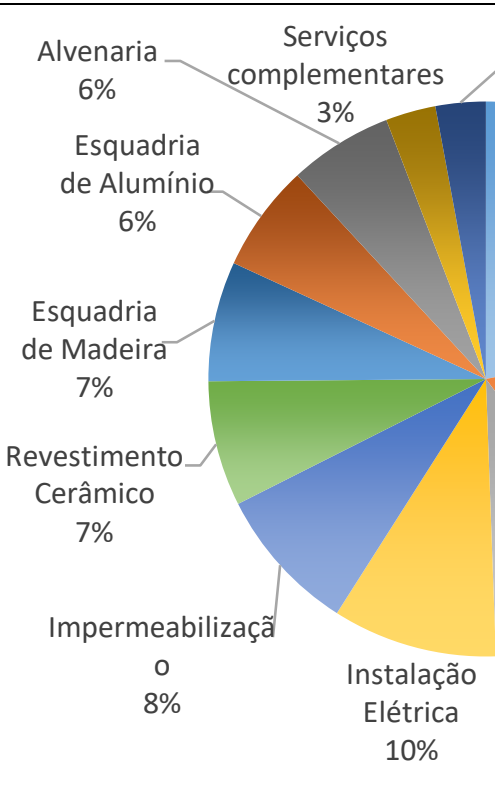 } & \multirow{13}{*}{$\begin{array}{l}\text { Pintura } \\
3 \% \\
\text { Instalação } \\
\text { Hidráulica } \\
22 \% \\
\text { Esquadria } \\
\text { de PVC } \\
18 \% \\
\\
\text { Outras Instalações } \\
10 \%\end{array}$} \\
\hline Instalação Hidráulica & 210 & & \\
\hline Esquadria de PVC & 171 & & \\
\hline Outras Instalações & 93 & & \\
\hline Instalação Elétrica & 92 & & \\
\hline Impermeabilização & 82 & & \\
\hline $\begin{array}{l}\text { Revestimento } \\
\text { Cerâmico }\end{array}$ & 70 & & \\
\hline Esquadria de Madeira & 67 & & \\
\hline Esquadria de Alumínio & 60 & & \\
\hline Alvenaria & 58 & & \\
\hline $\begin{array}{l}\text { Serviços } \\
\text { complementares }\end{array}$ & 28 & & \\
\hline Pintura & 28 & & \\
\hline TOTAL & 959 & & \\
\hline
\end{tabular}

Figura 8: Principais causas vinculadas as ocorrências de assistência técnica nos empreendimentos

Assim como já realizado de forma individual para os condomínios C, D e E, a Figura 9 traz as dez causas que apresentaram o custo mais elevado ao se agruparem os dados dos três estudos. Busca- 
se identificar os pontos onde ocorre o maior desembolso da verba da assistência técnica no âmbito global dos empreendimentos de alto padrão da empresa em análise.

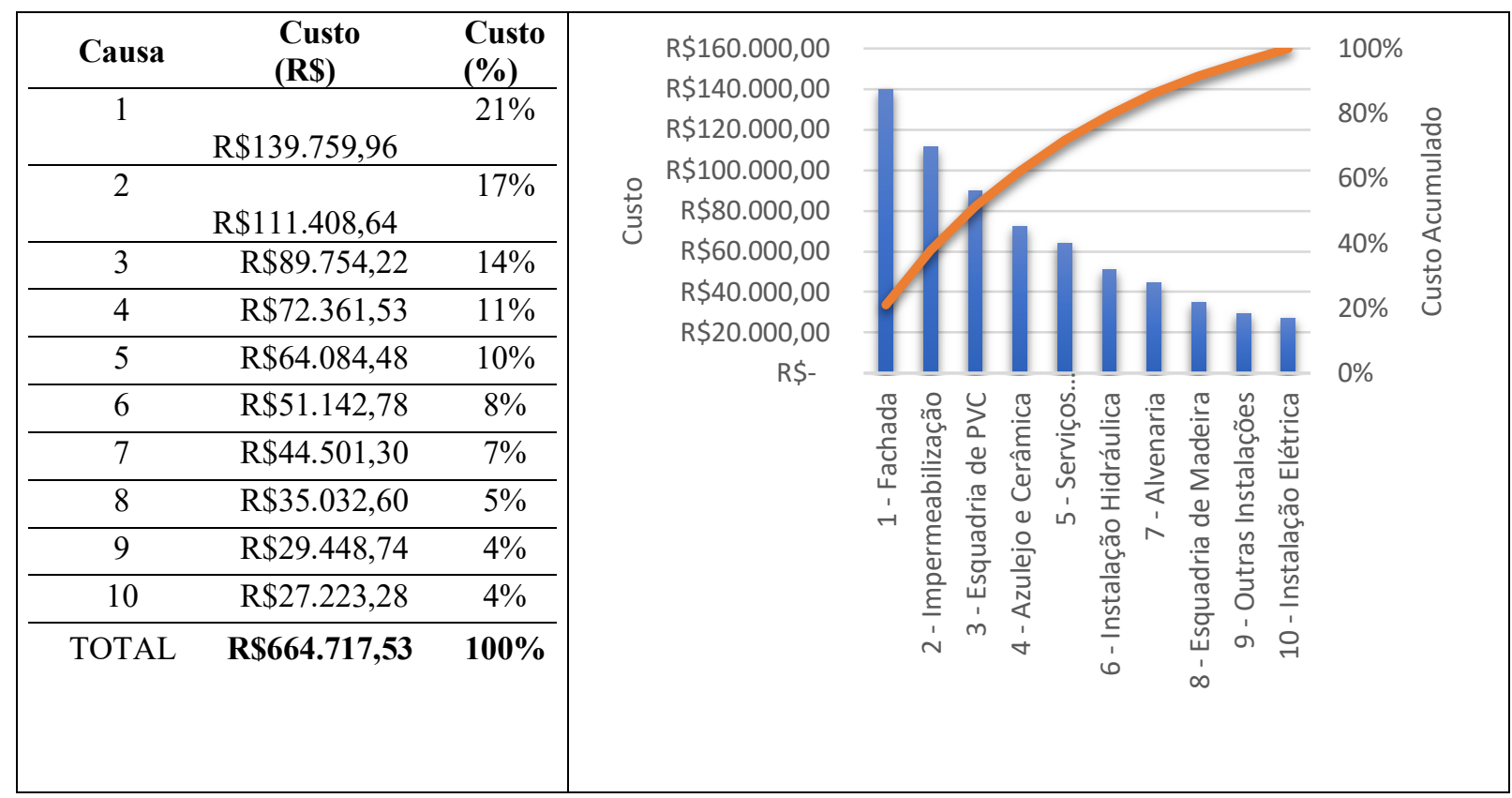

Figura 9: Principais custos relacionados as causas geradoras das ocorrências de assistências técnica nos empreendimentos C, D e E.

Os reparos com causa vinculada a fachada representam o maior custo entre os empreendimentos de alto padrão. Com um gasto perto de 140 mil reais em dois anos, este tópico não está entre os dez itens com maior número de ocorrências, mostrando-se assim um tópico negligenciado na análise, uma vez que a empresa tem sua visão voltada para a quantidade de chamados e não faz a vinculação com o custo de resolução. Além disso, cabe ressaltar que os condomínios $\mathrm{D}$ e E tiveram um alto custo vinculado a falhas na fachada, sendo a mesma composta por pastilhas e granitos, materiais de uso mais clássico, enquanto que no primeiro empreendimento analisado, que tem em grande parte o fechamento em pele de vidro o custo é reduzido. Este fato demonstra que as técnicas mais novas estão tendo um maior controle no momento da execução. As falhas no sistema de impermeabilização aparecem na segunda posição, com $17 \%$ do custo vinculado. Conforme discutido anteriormente, apesar de ter percentual baixo de ocorrências geradas ( $8 \%)$, a resolução desses problemas tem um alto custo devido a sua complexidade de diagnóstico e da dificuldade de reparos, sendo outro ponto que necessita ter um controle mais crítico no período de obra buscando evitar danos futuros.

Somando-se as causas com maior relevância para o custo, temos as esquadrias de PVC, que diferente dos tópicos anteriores, possui um alto número de ocorrências vinculadas. Com isso, apenas nos três primeiros tópicos da Figura 9, são acumulados 52\% do valor gasto em dois anos de assistência técnica para três empreendimentos. Outro custo que deve ser destacado é o associado ao reparo das falhas nas instalações hidráulicas, que apesar de representar a maior porcentagem entre o número de solicitações atendidas pela assistência técnicas o valor gasto não está entre os três primeiros, sendo de apenas $8 \%$ dentre os principais. Situação semelhante ocorre com as demais instalações, que conforme Figura 9, possuem um custo baixo, porém são vinculadas a uma grande quantidade de ocorrências resolvidas. Finalizando a análise, enquanto que as falhas nos revestimentos cerâmicos (11\%), serviços complementares (10\%), alvenaria (7\%) e esquadrias de madeira (5\%) somaram um custo de $33 \%$ o item de pintura não teve um custo associado significante 
quando avaliados os empreendimentos $\mathrm{C}, \mathrm{D}$ e $\mathrm{E}$ de forma conjunta, apesar de representar 3\% das ocorrências atendidas pela assistência técnica.

\section{CONCLUSÕES}

Pode-se observar a predominância de algumas causas no registro total de ocorrências, onde apenas nas três primeiras colocadas do ranking obteu-se $50 \%$ dos registros de reclamações, sendo elas: instalações hidráulicas, esquadria de PVC e outras instalações. Também foi possível constatar, pela verificação dos custos gerais, que nos reparos vinculados as falhas na fachada, impermeabilização e esquadrias de PVC, chegou-se a 52\% do valor gasto entre os dez mais altos. Esses resultados possibilitaram a empresa repensar no seu processo de atendimento ao cliente Classe A, onde por razões diversas é um cliente que espera que a assistência técnica seja imediata e assertiva, causando o menor impacto possível à sua rotina diária.

Visando aprimorar e qualificar o canal de comunicação com esses clientes foi aprimorado o serviço de atendimento ao cliente Classe A, pela empresa, onde estipularam que solicitações antes consideradas como fora de garantia, segundo o manual do proprietário com duração de tempo de 5 anos no máximo. A assistência técnica dos empreendimentos Classe A também conta com uma equipe operacional própria, que realizada principalmente as demandas que não se encontram mais no período de garantia dos fornecedores buscando diminuir o custo, aumentar a qualidade do serviço prestado e uma maior agilidade na resolução.

Outra ação foi a retroalimentação dos empreendimentos dos empreendimentos Classe A, onde as manifestações patológicas identificadas serviram de lição para os futuros lançamentos, tendo como foco diminuir o volume de problemas com a solução da causa dos mesmos em projeto. Outro ponto de retroalimentação foi o cruzamento dos custos e a solução do problema, onde foi possível tomar a decisão de não ter mais o prazo de garantia para o atendimento do cliente Classe $\mathrm{A}$, visto que a percepção negativa do cliente tem mais impacto nos negócios do que o custo para solucionar os problemas.

Essas conclusões vão de encontro com Schneider (2013) que enfatiza a importância da retroalimentação das informações colhidas no pós-ocupação e, também, com Silva Filho, Souza e Leão Filho (2015) que afirmam que a assistência técnica tem caráter corretivo. Destaca-se que um dos pontos mais importantes desse trabalho foi que a assistência técnica é primordial na tomada de decisão para novos produtos que serão lançados no mundo, conforme relatam Ara'jo, Mendes e Martins (2018).

Ao longo desse estudo ficou evidente que a avaliação periódica e sistemática, por parte das empresas, nas ocorrências geradas devido às solicitações de assistência técnica é importante para os futuros projetos e da própria empresa.

\section{REFERENCIAS}

ARAÚJO, D.C.; MENDES, J. A. N.; MARTINS, R. Z.; Gestão de Custos Aplicada à Indústria de Estruturas Pré-Moldadas Utilizadas em Construção Civil de Condomínios: estudo de caso. Revista H-Tec Humanidades e Tecnologia, v. 2, n. 2, p. 6-167, jul./dez., 2018.

Associação Brasileira de Normas Técnicas. (2006). NBR12721: Avaliação de custos unitários de construção para incorporação imobiliária e outras disposições para condomínios edifícios Procedimento.

Bautz, A. Conheça o perfil do consumidor de produtos e serviços de luxo. Disponível em:

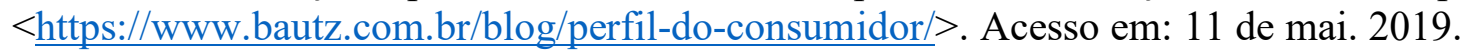


BRASIL. Código de defesa do consumidor - Lei 8078, de 11 de setembro de 1990. Dispõe sobre a proteção do consumidor e dá outras providências. Brasília, DF, 1990. Disponível em: < http://www.planalto.gov.br/ccivil 03/leis/18078.htm>. Acesso em: 22 de jun de 2019.

Laste, F. (2012), "Assistência técnica ao cliente: descrição das etapas do procedimento na construção civil, Trabalho de conclusão de curso - Escola de Engenharia, Universidade Federal do Rio Grande do Sul, Porto Alegre, p. 66.

FIGUERÊDO, P. (2017). Construção civil representa 6,2\% do PIB Brasil. Disponível em https://www.sistemafibra.org.br/fibra/sala-de-imprensa/noticias/1315-construcao-civil representa6-2-do-pib-brasil.html. Acesso em 14 de julho de 2021.

Instituto Brasileiro de Geografia e Estatística. (2020). IBGE: Pesquisa anual da indústria da construção. Rio de Janeiro, RJ, 2020. Disponível em: < https:/questionarios.ibge.gov.br/downloads-questionarios/paic-pesquisa-anual-da-industria-daconstrucao $>$. Acesso em 04 de ago de 2021.

LIMA, P. R. B. Consideração do projeto no desempenho dos sistemas construtivos e qualidade da edificação - Proposição de um modelo de banco de dados. Dissertação - UFMG. Belo Horizonte, 2005.

NETTO et al. Proposta de melhorias na gestão de empresas de construção civil: um estudo de caso internacional. INTERAÇÕES,Campo Grande, MS, v. 21, n. 3, p. 499-512, jul./set. 2020.

OLIVEIRA, L. A.; MITIDIERI FILHO, C. V. O projeto de edifícios habitacionais considerando a Norma Brasileira de Desempenho: análise aplicada para as vedações verticais. Gestão \& Tecnologia de Projetos, [S.I.], v.7, n.1, p.90-100, mai. 20012.

Ramos, I. S., Mitidieri Filho, C. V. (2007), Procedimentos de assistência técnica para construtoras. Revista Techne, 122. http://techne17.pini.com.br/engenhariacivil/122/artigo287440-8.aspx. Acesso em 20 de março de 2021

REZENDE, M. M., MELHADO, S. B., MEDEIROS, J. S. (2002). "Gestão da qualidade e assistência técnica aos clientes na construção de edificios" in: Congresso de Engenharia Civil, Juiz de Fora.

Laste, F. (2012), "Assistência técnica ao cliente: descrição das etapas do procedimento na construção civil, Trabalho de conclusão de curso - Escola de Engenharia, Universidade Federal do Rio Grande do Sul, Porto Alegre, p. 66.

SCHNEIDER, F. M. (2013), "Identificação das principais manifestações patológicas em epreendimentos residenciais com base nos dados das assistência técnica de uma empresa construtora", Trabalho de conclusão de curso - Escola de Engenharia, Universidade Federal do Rio Grande do Sul, Porto Alegre, p. 110.

SILVA FILHO, C. E., SOUZA, L. R., LEÃO FILHO, R. G. (2015), “Análise de dados pós obra como ferramenta de gestão da qualidade", Monografia de Trabalho de Conclusão de Curso, Universidade Federal de Goiás, Goiânia. 